\title{
Water supply patterns over Germany under climate change conditions
}

\author{
M. H. Tölle ${ }^{1}$, C. Moseley ${ }^{2}$, O. Panferov ${ }^{1}$, G. Busch ${ }^{3}$, and A. Knohl ${ }^{1}$ \\ ${ }^{1}$ Department of Bioclimatology, University of Göttingen, Büsgenweg 2, 37077 Göttingen, Germany \\ ${ }^{2}$ Max-Planck-Institute of Meteorology, and Helmholtz-Zentrum Geesthacht, Climate Service Center (CSC), Hamburg, \\ Germany \\ ${ }^{3}$ Bureau for Applied Landscape Ecology and Scenario Analysis (BALSA), Am Weissen Steine 4, 37085 Göttingen, Germany \\ Correspondence to: M. H. Tölle (mschlue@gwdg.de)
}

Received: 4 March 2012 - Published in Biogeosciences Discuss.: 27 April 2012

Revised: 1 March 2013 - Accepted: 24 March 2013 - Published: 2 May 2013

\begin{abstract}
A large ensemble of 24 bias-corrected and uncorrected regional climate model (RCM) simulations is used to investigate climate change impacts on water supply patterns over Germany using the seasonal winter and summer Standardized Precipitation Index (SPI) based on 6-month precipitation sums. The climate change signal is studied comparing SPI characteristics for the reference period 1971-2000 with those of the "near" (2036-2065) and the "far" (2071-2100) future. The spread of the climate change signal within the simulation ensemble of bias-corrected versus non-corrected data is discussed. Ensemble scenarios are evaluated against available observation-based data over the reference period 1971-2000. After correcting the model biases, the model ensemble underestimates the variability of the precipitation climatology in the reference period, but replicates the mean characteristics. Projections of water supply patterns based on the SPI for the time periods 2036-2065 and 2071-2100 show wetter winter months during both future time periods. As a result soil drying may be delayed to late spring extending into the summer period, which could have an important effect on sensible heat fluxes. While projections indicate wetting in summer during 2036-2065, drier summers are estimated towards the south-west of Germany for the end of the 21st century. The use of the bias correction intensifies the signal to wetter conditions for both seasons and time periods. The spread in the projection of future water supply patterns between the ensemble members is explored, resulting in high spatial differences that suggest a higher uncertainty of the climate change signal in the southern part of Germany. It is shown that the spread of the climate change signals between
\end{abstract}

SPIs based on single ensemble members is twice as large as the difference between the mean climate change signal of SPIs based on bias-corrected and uncorrected precipitation. This implies that the sensitivity of the SPI to the modelled precipitation bias is small compared to the range of the climate change signals within our ensemble. Therefore, the SPI is a very useful tool for climate change studies allowing us to avoid the additional uncertainties caused by bias corrections.

\section{Introduction}

Ongoing increases in the atmospheric $\mathrm{CO}_{2}$ concentration and associated climate changes are real. Recent extreme events have demonstrated Europe's vulnerability to natural hazards (Lloyd-Hughes and Saunders, 2002; Zaitchik et al., 2006) possibly related to climate change. Projected mean annual precipitation is expected to decrease in the mid-latitudes and to increase in the high latitudes (Christensen et al., 2007), with precipitation patterns shifting seasonally and changing regionally, and thus raising the risk for extremes such as droughts in one area and floods in the other. Continued occurrence of such weather events may result in possible crop failure and decrease in yield (Iglesias et al., 2012), runoff and erosion risks, forest fires (Pausas, 2004), increase of pollutants in water bodies, social alarm (Palutikof et al., 2004), illness, and increasing irrigation (Schär et al., 2004; Bartholy et al., 2009). A decrease of water resources due to decreasing precipitation (DeGaetano, 1999) and increasing evapotranspiration can significantly influence the drinking water 
supply, which is relevant for agricultural management (Wilhite et al., 2000; Kundzewicz, 2003).

Besides that, the increasing emissions of greenhouse gases and increasing prices for fossil fuels have highlighted the demand for $\mathrm{CO}_{2}$ "neutral" renewable energy sources such as bioenergy, e.g. agroforestry systems or short rotation poplar coppices. However, the efficiency of these energy sources depends on their productivity, which in turn depends on water availability and extreme weather events among other factors. Thus, to estimate success or failure of such systems in the present and the future, and to plan optimal adaptation and mitigation strategies, information on observed and future climate is required as well as risk assessment based on climate information.

It is acknowledged that climate change may alter the precipitation pattern and potential of hydrological risks over large regional scales. For example, the global multi-model ensemble of SRES (Special Report on Emission Scenarios) scenario A1B projected for Germany an increase of winter (DJF) and decrease of summer (JJA) precipitations at the end of the 21 st century. An increase in variability of precipitation intensity as well as of the number of dry days was projected (Meehl et al., 2007). However, the projected seasonal climate variability required for climate impact analysis and adaptation strategies needs to be considered on a regional scale, e.g. Olesen et al. (2007), since the regional and local climate, besides the quality of the location, constitutes a major component of farming. Previous climate projection studies for the 21st century, carried out for Europe with regional climate models within the PRUDENCE project (Christensen and Christensen, 2007; Christensen et al., 2007), showed similar trends as the global projections. Analogous results were obtained earlier by Gerstengarbe et al. (2003) for the German federal state Brandenburg for the A1B scenario modelled by ECHAM4. Under A1B the downscaled projected annual precipitation will remain almost unchanged, while winter precipitation will increase and summer precipitation will decrease.

To characterize present and projected future water supply based on climatological data, several drought indices could be applied like the Palmer Drought Severity Index (PDSI) (Palmer, 1965) or the Standardized Precipitation Index (SPI) after McKee et al. (1993). We further refer to an in-depth description of different indices used to characterize drought in Seneviratne et al. (2012). Complex indices like the PDSI implement several different meteorological and soil variables, each of which has its own observation uncertainty or model bias. To decrease the uncertainty we have chosen the SPI which is based on precipitation only. It was successfully applied to describe regional future water supply conditions for boreal and Mediterranean regions on a regional scale (Galos et al., 2007; Anav and Mariotti, 2011). There are also other studies using the SPI for projections on a global scale like Burke and Brown (2008).
It is well known that the simulation results of climate models might systematically differ from observations. This difference - the so-called model bias - can be so large that the model results cannot be reasonably used for climate impact studies (Teutschbein and Seibert, 2012). Thus, a bias correction should be applied (Piani et al., 2010; Berg et al., 2012). The procedure is not universally advisable as it changes the physical consistency of model output and should be implemented only when necessary. The SPI is based on precipitation only. The advantage of using the SPI is that for our study bias-corrected precipitation data are readily available, thus allowing us to study the importance of bias correction for a drought index.

Our primary aim is to characterize climate change driven variations in future water supply conditions and their spatial variability over Germany using SPI based on projected precipitation using a range of emission scenarios and regional climate models. The secondary aim of the article is to estimate whether the precipitation data should be bias-corrected or not for the analysis of the projected SPI.

\section{Methods}

\subsection{Study area}

The whole of Germany is considered for analysis. The northern part of Germany is influenced by the Atlantic, North and Baltic seas with advective rainfall, representing a maritime climate. Towards the south the climate becomes more transient where oceanic climate-aspects diminish and continental characteristics gain more impact, being land-dominated by advection from the surrounding land areas. The southern part of Germany is influenced by the Alpine mountains.

\subsection{Scenarios and model}

The data used are the climate scenarios based on emission scenarios A1B, A2 and B1 with different greenhouse gas and aerosol concentrations and the control scenario C20 described in the Special Report on Emission Scenarios (Nakicneovic et al., 2000). While A1B includes rapid introduction of new and more efficient technologies, B1 is more focused on environmental sustainability comprising reductions in material intensity and the introduction of clean and resource efficient technologies. A2 is the least sustainable scenario describing a continuously increasing population and economic growth.

Our analyses are based on two regional climate models (RCMs) driven by one global model, ECHAM5/MPI-OM (MPI-M, 2006; Roeckner et al., 2006): the non-hydrostatic COSMO-CLM (CCLM) (Will et al., 2006) with a downscaling to a $0.165^{\circ}(\approx 18 \mathrm{~km})$ horizontal resolution and the hydrostatic RCM REMO (Jacob et al., 2007) with a downscaling to a $0.088^{\circ}(\approx 10 \mathrm{~km})$ horizontal resolution. Both RCMs calculate the relevant 
Table 1: List of the considered model ensemble of regional climate simulations.

\begin{tabular}{cccc}
\hline Model & Time period & Simulation & Total run \# \\
\hline CCLM & $1960-2000$ & C20 & 2 \\
CCLM & $2001-2100$ & A1B & 2 \\
CCLM & $2001-2100$ & B1 & 2 \\
REMO & $1950-2000$ & C20 & 3 \\
REMO & $2001-2100$ & A1B & 3 \\
REMO & $2001-2100$ & B1 & 3 \\
REMO & $2001-2100$ & A2 & 2 \\
\hline
\end{tabular}

physical processes dynamically. The considered model ensemble of regional climate simulations comprises the following experiments: for CCLM, two C20 control simulations (1960-2000), and two A1B and two B1 simulations for the time period 2001-2100; for REMO, three C20 control simulations (1950-2000), and three A1B, three B1, and two A2 simulations for the time period 2001-2100 (see also Table 1).

All simulations within the ensemble are treated with equal weight, regardless of model and scenario. This ensemble of simulations enables a more robust evidence of climate change relative to single realisations. The simulation data of these two RCMs over Germany are analysed for the period 1971 to 2100 . The "middle" 2036-2065 and "far" 20712100 future periods are chosen for investigations.

\subsection{Bias correction}

Precipitation simulated by climate models might deviate from observations. This systematic deviation is usually called bias. The bias indicates the necessity of model improvements. It could be argued that the model bias influences only the absolute model values and the simulated relative climate change signal can be used. However, many climate impact studies need the real range of changes. Therefore, different correction methods are applied by the scientific community for successful impact modelling including the deltachange approach (Mudelsee et al., 2010; Themessl et al., 2011). In the present study a bias correction method (quantile mapping) after Piani et al. (2010) is applied to the modelled data. This climate model bias correction may be useful for long-term statistical analysis to quantify changes in precipitation. Themessl et al. (2011) compared different bias correction methods and found quantile mapping after Piani et al. (2010) to perform best. The correction method constructs a transfer function which maps the cumulative distribution function of the simulated daily precipitation sums to that of a given observational data set in the control period of the climate simulation. This transfer function is then applied to the entire climate scenario simulation under the assumption of stationarity. The gridded daily precipitation data set REGNIE (which stands for Regionalisierung von Niederschlagshöhen - regionalisation of precipitation) (DWD, 2009) is aggregated to the CCLM grid and used for bias estimation and correction. An additional assumption is that the transfer functions are invariant in time.

\subsection{Standardized Precipitation Index}

To assess deficit or excess of moisture conditions in Germany, the Standardized Precipitation Index (SPI) after McKee et al. (1993) is calculated, addressing meteorological and, indirectly, agricultural drought. The precipitation time series from climate projections as described above are used for the SPI. This dimensionless index can quantify the precipitation deficit or surplus for multiple timescales. It is based on the long-term probability distribution of precipitation in a grid cell by using the two-parameter gamma distribution estimated by the maximum likelihood method. The SPI has been shown to be relevant for drought reconstruction and drought monitoring and can be derived for different time and spatial scales (Lana et al., 2001; Lloyd-Hughes and Saunders, 2002; Wu et al., 2005). Burke and Brown (2008) showed that changes in SPI are generally correlated with several other drought indices which also take potential evapotranspiration and temperature into account. They found that the SPI shows little change in drought compared to other indices, and found that the PDSI tends to overestimate drought. Here, the SPI is calculated for summer and winter season on a 6-month timescale. For a stable estimation of the gamma distribution parameters, the required length of record needs to be longer than 80 years (Wu et al., 2005), therefore, the period 1971 to 2100 is used for estimating SPI. Positive SPI values between 0.5 and 2 indicate higher than median precipitation, i.e. wet conditions. The SPI values above 2 denote extremely wet conditions. Correspondingly, the negative values between -0.5 to -2 indicate less than median precipitation, i.e. dry conditions, and values below -2 extremely dry conditions.

\subsection{Quantile regression}

To estimate trends in all parts of the variable distribution in seasonal SPI time series, quantile regression is applied. This method identifies not only the response in the mean of the variable distribution of some predictor variables as in ordinary least squares regression, but in all quantiles of the distribution of the response variable. In classical linear regression, the response variable $Y$ is related linearly with $X$ by $Y=\beta X+\gamma$, where the coefficients $\beta$ and $\gamma$ are the slope and the intercept, respectively. In this case the coefficient values for $\beta$ and $\gamma$ are found by minimizing the sum of squared residuals. For quantile regression each quantile, $\lambda$, of the response variable $Y$ is determined by estimating each quantile slope $\beta_{\lambda}$ and intercept $\gamma_{\lambda}$ by minimizing the asymmetrically 
Table 2: Range of precipitation climate change signals of ENSEMBLES and REMO/CCLM (2071-2100 relative to 19712000).

\begin{tabular}{ccc}
\hline & ENSEMBLES & REMO/CCLM \\
\hline Summer & $-25 \%-+5 \%$ & $-18 \%-+10 \%$ \\
Winter & $-4 \%-+20 \%$ & $+10 \%-+30 \%$ \\
\hline
\end{tabular}

weighted sum of absolute residuals (Koenker and Hallock, 2001). Standard deviations of the estimated trend coefficients for each year are derived with bootstrapping by taking into account the three consecutive winter or summer months of each year. Significance of the slopes are estimated at the $5 \%$ significance level (two-tailed test).

\subsection{Climate change signal}

Climate change impacts on water supply patterns are investigated by comparing SPI characteristics over Germany during the reference period 1971-2000 with those of future scenarios over the chosen periods 2036-2065 and 2071-2100. Our analysis includes the climate change signal (CCS) in the ensemble mean SPI. It is calculated for each simulation individually as a difference between the projected ensemble's mean SPI averaged over one of the future periods and a control period representing the current ensemble's mean SPI (19712000). The mean change signal of the simulations will be compared to the maximum spread within the ensemble scenarios (12 uncorrected and 12 bias-corrected RCM simulations). A detailed description about this comparison method is given in Hagemann et al. (2009). To evaluate the necessity and the effect of the model bias, the spread within the simulation ensemble in relation to the climate change signal of corrected versus non-corrected data is analysed.

To assess the relevance of our results along with existing studies including ENSEMBLES (http://www.ensembles-eu. org, Heinrich and Gobiet (2012)), additional information on precipitation CCS between ENSEMBLES and our results is included in this study. A comparison of the climate change signals of the REMO/CCLM ensemble used in our manuscript with the simulations within the ENSEMBLES project (Hewitt, 2004) is given in Jacob et al. (2012). The ENSEMBLES simulations have a horizontal resolution of about $25 \mathrm{~km}$, and are based on only one emission scenario, namely A1B. The REMO/CCLM ensemble is more highly resolved over Germany ( $18 \mathrm{~km}$ for CCLM, $10 \mathrm{~km}$ for REMO) and includes three emission scenarios (A1B, A2, B1). At the end of the 21st century (2071-2100), the ENSEMBLES simulations project a precipitation change in Germany with respect to $1971-2000$ between $-4 \%$ and $+20 \%$ in winter, and a change between $-25 \%$ and $+5 \%$ in summer.
For the REMO/CCLM ensemble, including all three emission scenarios, a clear increase between $+10 \%$ and $+30 \%$ is projected in winter, and a change between $-18 \%$ and $+10 \%$ is projected in summer with the majority of the simulations showing a decrease (see also Table 2). It becomes clear that the range spanned by the ENSEMBLES simulations is larger than that of the REMO/CCLM ensemble (Jacob et al., 2012), despite the fact that ENSEMBLES includes only one emission scenario. The main reason is that the REMO/CCLM ensemble is driven by only a single global climate model (ECHAM5/MPI-OM) and therefore cannot account for the uncertainty generated by the global models. The global models used in ENSEMBLES are described in van der Linden and Mitchell (2009).

\section{Results}

We compare winter and summer seasonal characteristics of observed precipitation of the REGNIE data set with simulated precipitation of CCLM (comprising two control runs) and REMO (comprising three control runs) averaged over Germany to identify whether the model data differ systematically from the observations, i.e. have a bias. Figure $1 \mathrm{a}$ and $\mathrm{b}$ show the median and standard deviation including quantiles and outliers for winter (DJF) and summer months (JJA), respectively, covering the reference period 1971-2000. Simulated median winter precipitation is overestimated by CCLM in all runs. REMO shows a large bias in run 2 only, while runs 1 and 3 are very close to the observed median precipitation. The median summer precipitation is overestimated by all models and runs. The variance is underestimated relative to the observations for winter, whereas the RCMs overestimate the variance for summer. All models fail to reproduce the asymmetrical distribution in winter (shift to lower values). In summer the observed distribution is more symmetrical with two (one CCLM and one REMO) of the five model runs reproducing it well. Another three runs show asymmetrical distributions. Thus, both REMO and CCLM produce biased results for Germany for mean precipitation as well as for precipitation variability and distribution. Therefore, the bias is corrected for all runs. The effect of the bias correction is demonstrated in Fig. 1a and b. It is obvious that the bias correction for winter months reduces the mean values so that all models and runs underestimate the mean precipitation. However, this underestimation is not significant $(5 \%$ significance level, $U$ test). The bias correction for the summer months improves the agreement between observed and modelled median precipitation considerably. The variance is also improved both for summer and winter, except for winter precipitation of REMO run 1.

The bias correction is then applied to modelled climate projections. Expectedly, the bias correction reduces the projected precipitation in all climate scenarios and runs both for CCLM (A1B and B1) and REMO (A1B, B1, and A2 

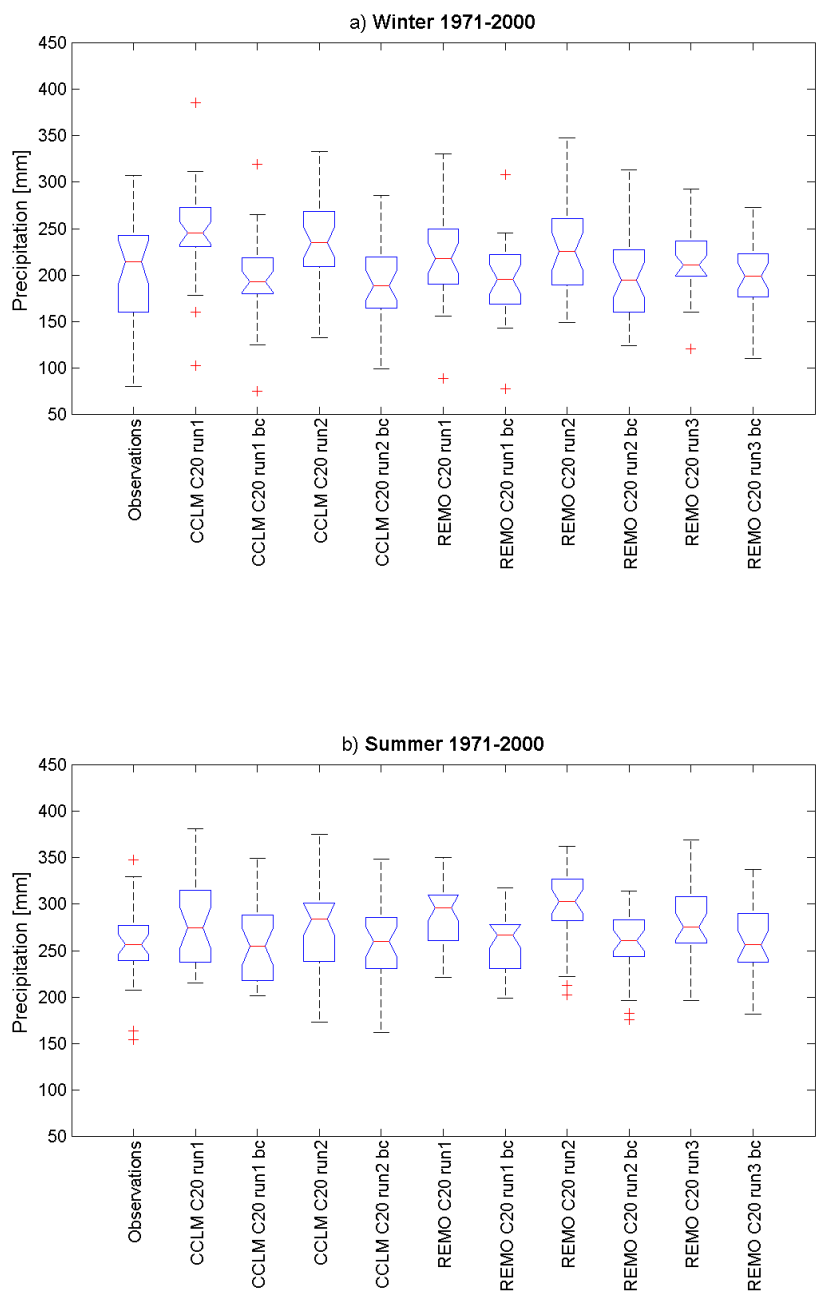

Fig. 1: (a) Seasonal winter (DFJ) medians of observed REGNIE, simulated precipitation (CCLM C20 run 1 and run 2; REMO C20 run 1 to 3 ), and bias-corrected (bc) simulated precipitation of CCLM and REMO averaged over the whole of Germany with the associated standard deviations for the reference period 1971-2000. (b) Seasonal summer (JJA) medians of observed REGNIE, simulated precipitation (CCLM and REMO), and bias-corrected simulated precipitation averaged over the whole of Germany with the associated standard deviations for the reference period 1971-2000. Central line: median; bottom and top of box: 25th and 75th percentiles; whiskers: data range; crosses: outliers.

comprising two runs) (see Fig. 2 for the period 2001-2100). Less reduction due to bias correction in the summer climate parameters of the CCLM is notable. See the Supplement for the same analyses but for the SPI.

Future seasonal changes in water supply patterns are investigated by the climate change signal in the SPI. The SPI is calculated on bias-corrected and uncorrected data and is presented as absolute differences. The CCS is calculated as the difference between the 30-year ensemble mean of the scenarios and the control simulations. Figure 3 shows that the RCMs simulate a general increase in mean SPI (increasing wetness) over Germany both in winter and in summer for the mid-century (2036-2065); however, the increase in summer is weaker. The signal shows a north-south gradient in winter with ensemble mean changes ranging from 0.1 in the south of Germany to 0.8 in the north, indicating normal to moderate changes. In summer the geographic distribution of CCS is not that evident - only a weak north-east to south-west gradient (CCS $\approx 0.4-0.8$ and 0.1 , respectively) is recognized. On the whole a notable increase (CCS is about 0.3) in the SPI is simulated over Germany in summer for 2036-2065 compared to the reference period (Fig. 3c).

Figure $3 \mathrm{~b}$ and $\mathrm{d}$ show the CCS for bias-corrected data. The direct comparison to Fig. $3 \mathrm{a}$ and $\mathrm{c}$ demonstrates that the bias correction increases the CCS both for summer and winter without altering much the spatial distributions and gradients. Since it is shown in Figs. 1 and 2 that bias correction reduces the modelled precipitation for both the control run and the projections, this increase of CCS indicates that the bias correction has a stronger effect on the $\mathrm{C} 20$ simulations than on the projections.

The CCS for winter SPI gets even stronger in 2071-2100 (Fig. 4a), which indicates increasing winter wetness at the end of the century. The spatial distribution, i.e. north-south gradient remains unchanged: the northern part of Germany is projected to experience a future wetter winter climate (increase of SPI by 0.8) than the southern part (increase of SPI by 0.2 ). This gradient demonstrates the oceanic influence in the north. The bias correction increases the winter CCS also for the end of the century (Fig. 4b). With corrected model data, more areas, especially in east-central Germany, experience future wetter winters (increase of SPI by 0.2). The CCS for summer 2070-2100 shows a qualitatively completely different tendency of climate development in Germany (Fig. 4c). While narrow zones at the northern and eastern edges of Germany are getting wetter (by 0.4 ) just like in the mid-century, the largest part of the country experiences drying (moderate droughts) at the end of the 21 st century (2071-2100). The drying increases towards the south and west. The bias correction contributes to the "wetting" of CCS also for the summer season. Fig. $4 d$ demonstrates that the "drying" of CCS is considerably reduced ( 0.1 of difference) by bias correction almost everywhere in Germany except for a few small "dry spots" in the Alps where CCS goes down from -0.1 to -0.5 .

To compare the effect of bias correction on CCS with the "natural" spread of CCS within the multimodel ensemble, we estimate for Germany: (1) the range (maximum-minimum) of the climate change signal of the uncorrected ensemble, i.e. including all CCLM and REMO simulations for the different considered emissions scenarios (A1B, B1, A2), and (2) the difference between the CCS of the corrected and uncorrected ensemble mean for both time 

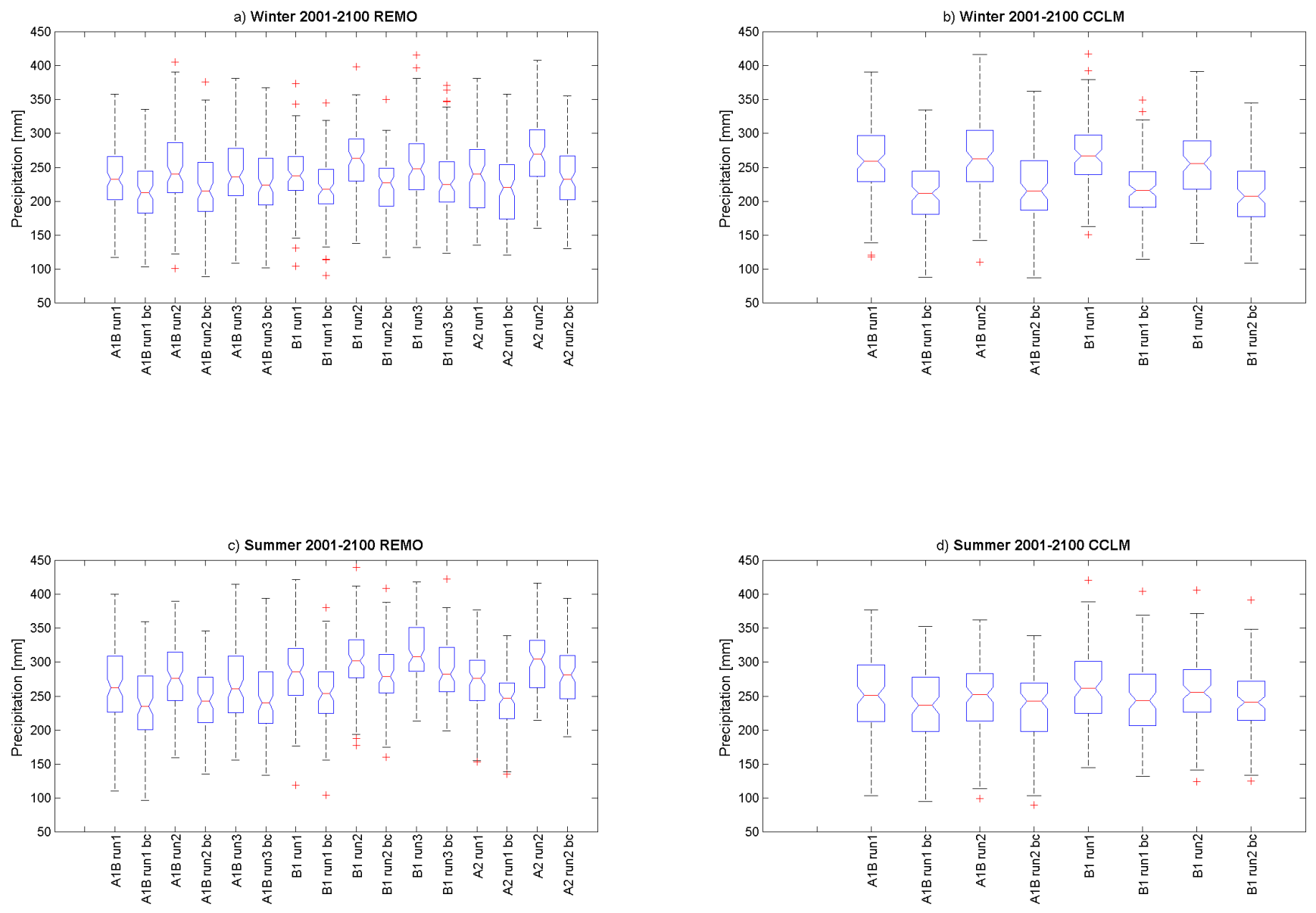

Fig. 2: (a) Seasonal winter (DFJ) medians of projected precipitation of REMO and bias-corrected (bc) projected precipitation of REMO averaged over the whole of Germany for the period 2001-2100. (b) Seasonal winter (DFJ) medians of projected precipitation of CCLM and bias-corrected (bc) projected precipitation of CCLM averaged over the whole of Germany for the period 2001-2100. (c) Seasonal summer (JJA) medians of projected precipitation of REMO and bias-corrected projected precipitation of REMO averaged over the whole of Germany for the period 2001-2100. (d) Seasonal summer (JJA) medians of projected precipitation of CCLM and bias-corrected projected precipitation of CCLM averaged over the whole of Germany for the period 2001-2100. Central line: median; bottom and top of box: 25th and 75th percentiles; whiskers: data range; crosses: outliers.

periods. The seasonal maximum and minimum differences between the CCS of the ensemble members are shown for each grid cell in Fig. 5a and c for 2036-2065 and Fig. 6a and c for 2071-2100.

The results in Fig. 5a show that all models, scenarios and runs describe the changes of winter precipitation in 20362065 in a rather similar way over the whole of Germany. The ensemble range (or spread) of SPI's climate change signal varies from weak (0.2) to moderate (1.4) without any distinct spatial pattern. Figure $5 \mathrm{~b}$ demonstrates that bias correction has almost no effect on the winter climate change signal in 2036-2065; its contribution (about 0.1) is much lower than the intra-ensemble variability of CCS.

In the summer season of the 2036-2065 period, the ensemble range of CCS strongly increases and the spatial south- north gradient appears. The maximal disagreement between ensemble members is observed in the south $(>1.9)$, and the best agreement in the north-west (down to 0.2). The effect of bias correction on CCS becomes more visible but remains small. There are small patches of weak positive changes $(0.2)$ in central Germany and a narrow range of negative changes $(-0.2)$ along the southern border. Again, it is obvious that the effect of bias correction is negligible compared to CCS differences within the ensemble.

For 2071-2100, the differences in the increase or decrease of precipitation projected by different scenarios and models get larger with the increasing spread within the ensemble. Figure 6a demonstrates that even the winter CCS is described quite differently by different ensemble members. The ensemble spread changes rather abruptly from the 


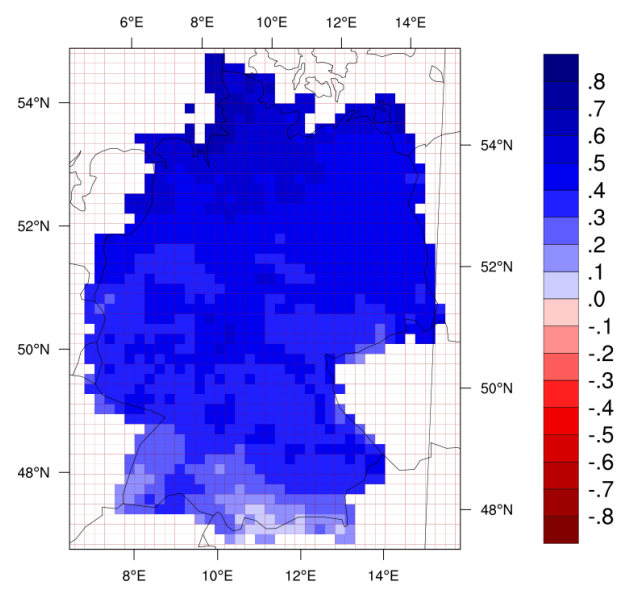

(a) Winter

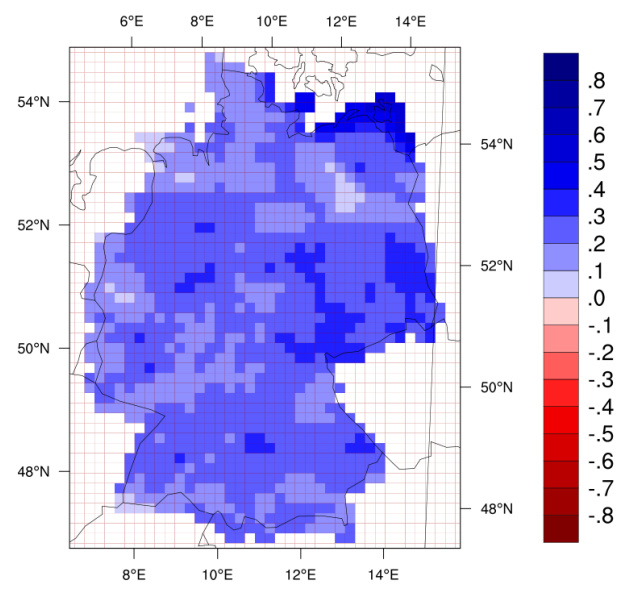

(c) Summer

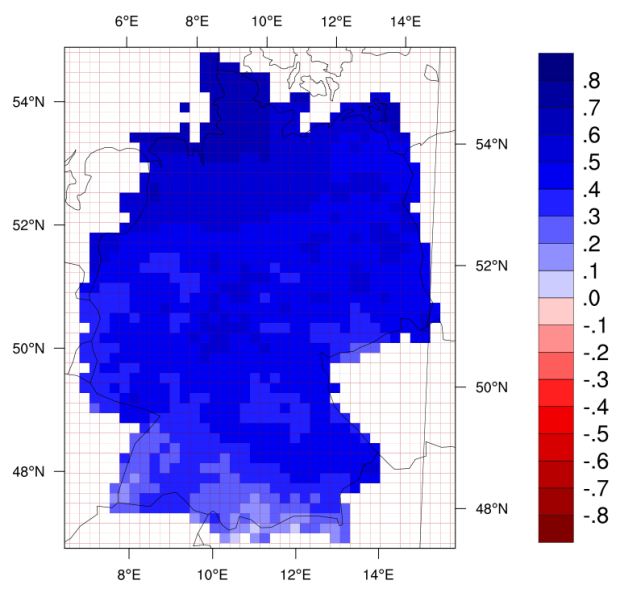

(b) Winter, bias corrected

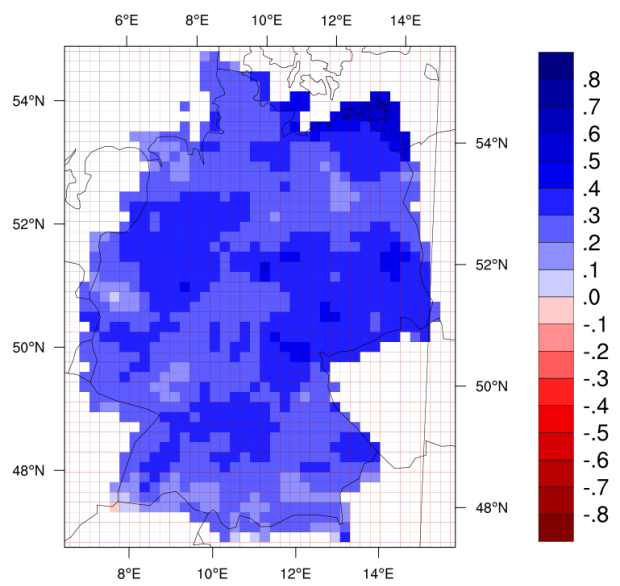

(d) Summer, bias corrected

Fig. 3: Mean climate change signal in SPI: difference of SPI between 2036-2065 and 1971-2000 for all runs for (a) winter uncorrected, (b) winter with model data estimated by bias correction, (c) summer uncorrected, and (d) summer with model data estimated by bias correction.

north-eastern part, with better ensemble agreement (low to moderate spread values of $0.2-1.1$, to the south-western part, with high disagreement and values up to 1.9 and higher. Still, the bias correction effect remains as low as for 20362065 - about 0.1 for the whole of Germany (Fig. 6b).

The spread of CCS signal within the ensemble increases dramatically for the summer period of 2071-2100. Only for small parts in northern and north-eastern Germany are the values moderate (around 0.6 to 1 ) and for the rest of the country the projected precipitation changes are quite different the CCS spread values vary from high to very high $(>1.9)$. The bias correction effect on CCS is slightly higher for the summer than for the winter season and, similarly to the period 2036-2065, induces weak positive changes in central and weak negative changes in southern parts of Germany. Still it remains much lower than the spread of CCS within the ensemble.

Comparing Figs. 5 and 6 it should be noted that for the period 2036-2065 the best CCS agreement between ensemble members (model/scenario/run) is roughly for northern and north-western Germany, but for the end of century the best agreement between CCS projections is for eastern and northeastern Germany. Thus, the results show that the bias correction has only minimal effect on the climate change signal of SPI for the whole 21st century, and it is negligible compared to the intra-ensemble variations of CCS. It can thus be concluded that the analysis of future water supply based on SPI does not require bias correction, and therefore the 


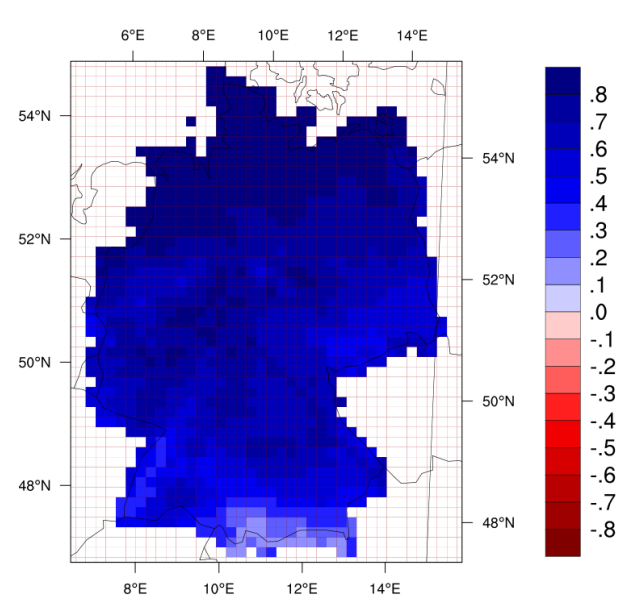

(a) Winter

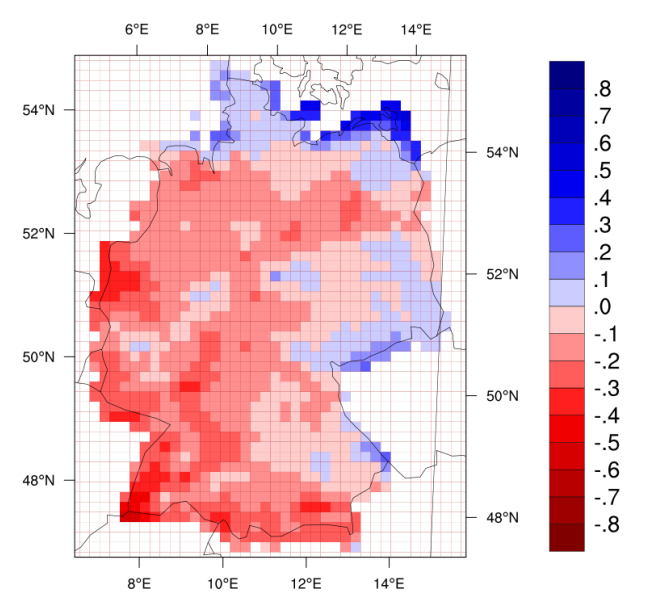

(c) Summer

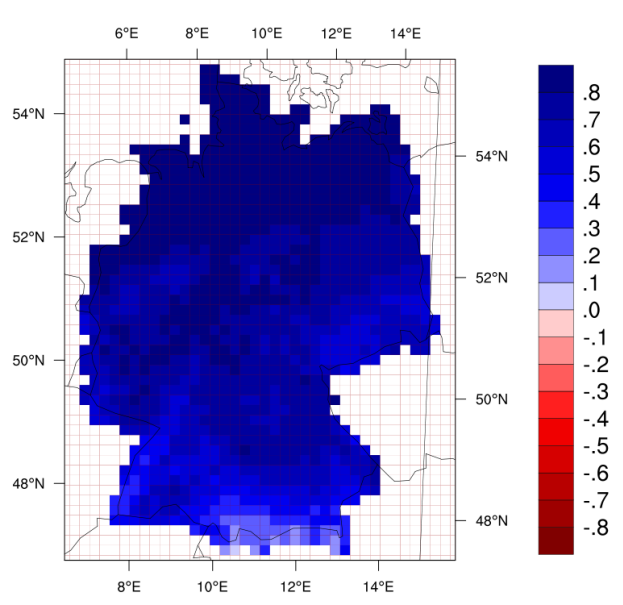

(b) Winter, bias corrected

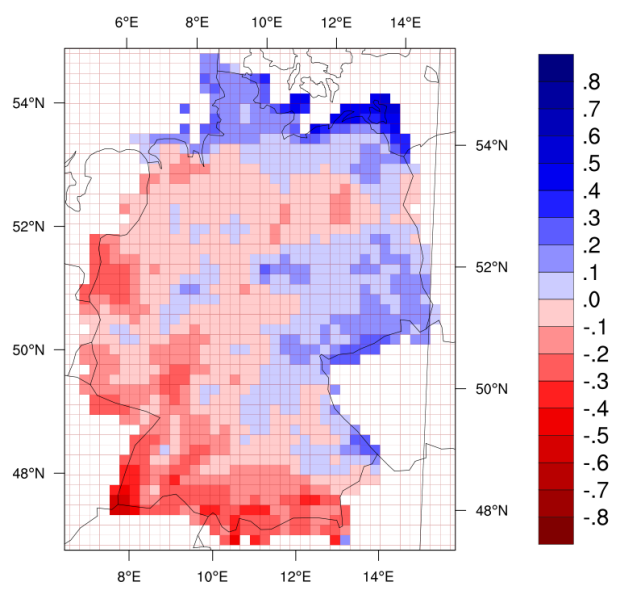

(d) Summer, bias corrected

Fig. 4: Mean climate change signal in SPI of all runs: difference of SPI between 2071-2100 and 1971-2000 for (a) winter uncorrected, (b) winter with model data estimated by bias correction, (c) summer uncorrected, and (d) summer with model data estimated by bias correction.

further analysis - quantile regression - is performed with uncorrected data.

In order to identify trends in all quantiles of the precipitation distribution, the ensemble mean slopes of the 130year SPI values are determined for quantiles ranging from 0.2 to 0.8 with quantile regression analysis. The trend significance is estimated with bootstrapping. SPI trend coefficients for winter time series of the period 1971 to 2100 depict future wetter winters over the whole of Germany with significant trends in the higher quantiles (quantiles $0.4-0.8$, Fig. $7 \mathrm{a}$ ). The lower quantiles $0.2-0.6$ of summer SPI coefficients indicate a trend towards drier conditions, whereas the upper quantile 0.8 shows a weak trend towards wetter conditions (Fig. 7b). However, the changes in the summer SPI quantiles over the whole of Germany are insignificant. The total increases in winter SPI for the time period 1971-2100 vary between $60 \%$ to $90 \%$ (see Fig. 8). For the same period a total decrease of $9 \%$ to $20 \%$ is determined for summer SPI quantiles $0.2-0.6$, and a total increase of $7 \%$ to $14 \%$ for the two upper quantiles.

\section{Discussion and conclusions}

This study provides analyses of how water supply patterns based on the SPI might change in the future over Germany based on an extended regional climate model ensemble. The SPI is based solely on precipitation for which bias-corrected data were readily available. Many studies (e.g. Sen et al. 


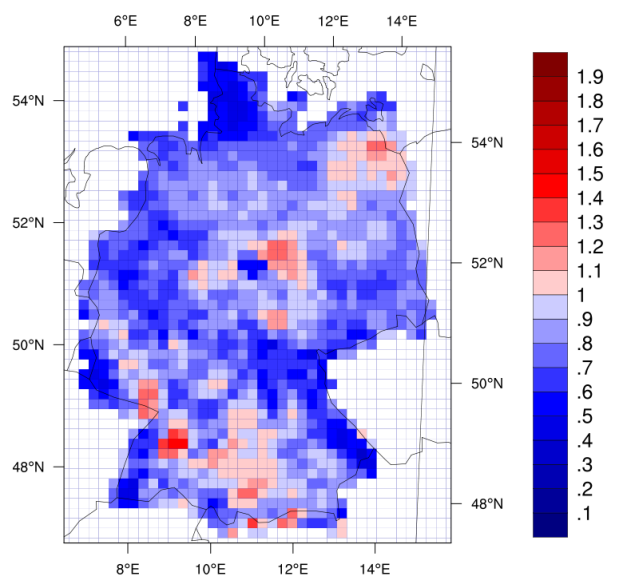

(a) Winter, difference between uncorrected ensembles

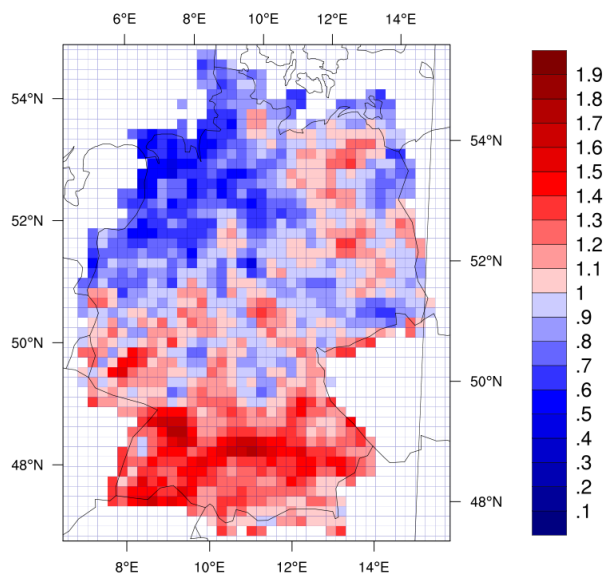

(c) Summer, difference between uncorrected ensembles

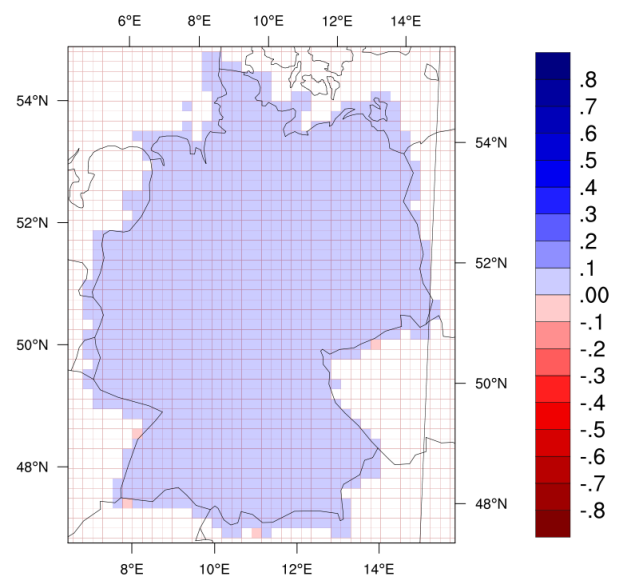

(b) Winter, difference between

CCS uncorrected and corrected

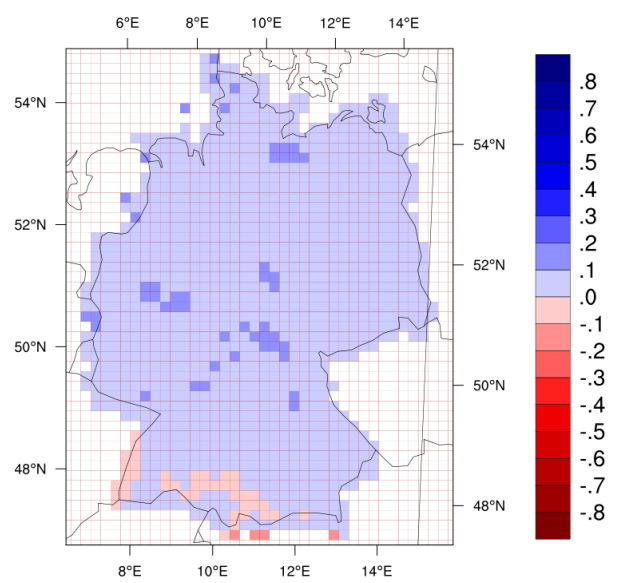

(d) Summer, difference between

CCS uncorrected and corrected

Fig. 5: For 2036-2065, (a) range of climate change signals in SPI between uncorrected scenarios in winter, (b) difference between the mean climate change signal in SPI of bias-corrected and uncorrected model data in winter, (c) range of climate change signals in SPI between uncorrected scenarios in summer, and (d) difference between the mean climate change signal in SPI of bias-corrected and uncorrected model data in summer.

(2012); Subash and Mohan (2011); Kalbarczyk (2010); Patel et al. (2007)) have shown that the SPI is relevant to vegetation, and there is a relationship between the SPI and productivity. Here, we demonstrate the possible changes in SPI under projected climate conditions and show the relation between the effect of model bias and the variability range of different models and model runs (simulations) over Germany.

The members of the regional climate model ensemble are evaluated against observation-based reference data. The simulations generally overestimate the mean and underestimate the variability of precipitation in the historic climate.
The bias correction improves those values. It is arguable to what extent the correction method helps to improve statistically higher moments, especially regarding outliers (see also Teutschbein and Seibert (2012)). On the one hand, it is quite difficult to assess the true quality of the bias-corrected data since they are limited by the quality of the observations, and on the other hand the climate models do not reproduce all observed features (Dosio and Paruolo, 2011) which cannot be accounted for by the bias correction method used for this study. A possible improvement could be achieved by a cascade bias correction method which accounts for 


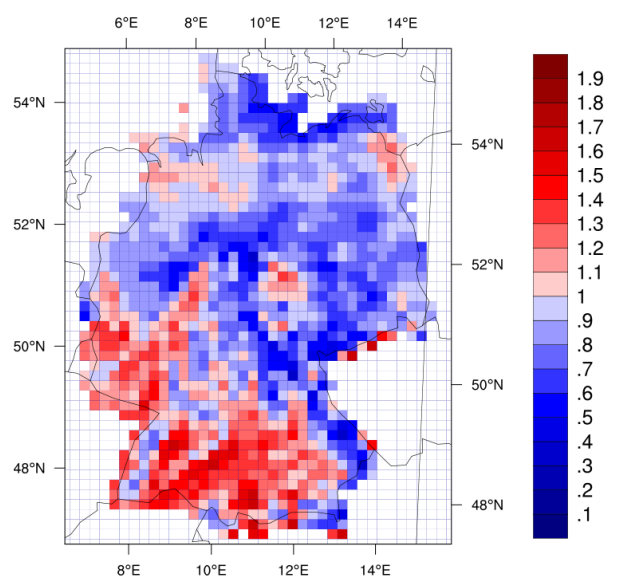

(a) Winter, difference between uncorrected ensembles

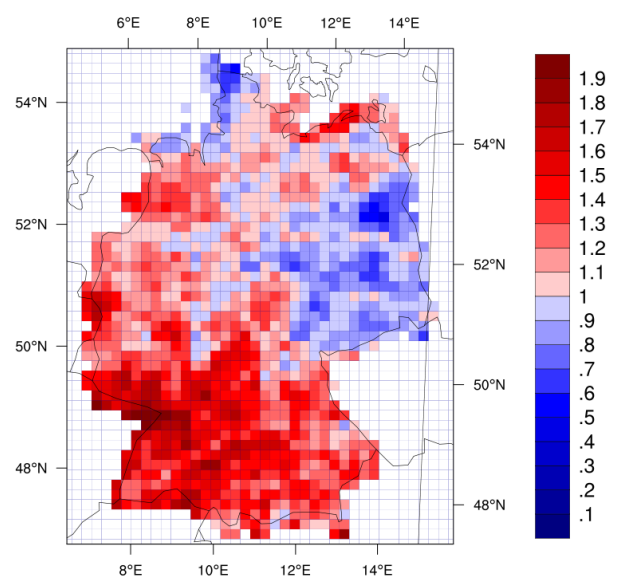

(c) Summer, difference between uncorrected ensembles

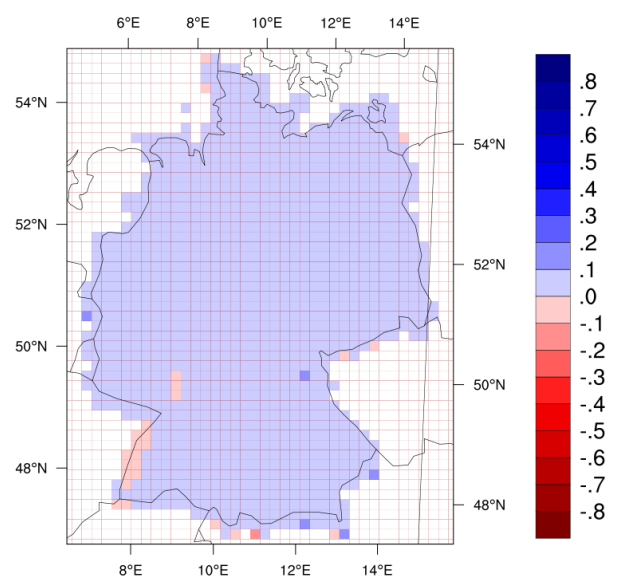

(b) Winter, difference between

CCS uncorrected and corrected

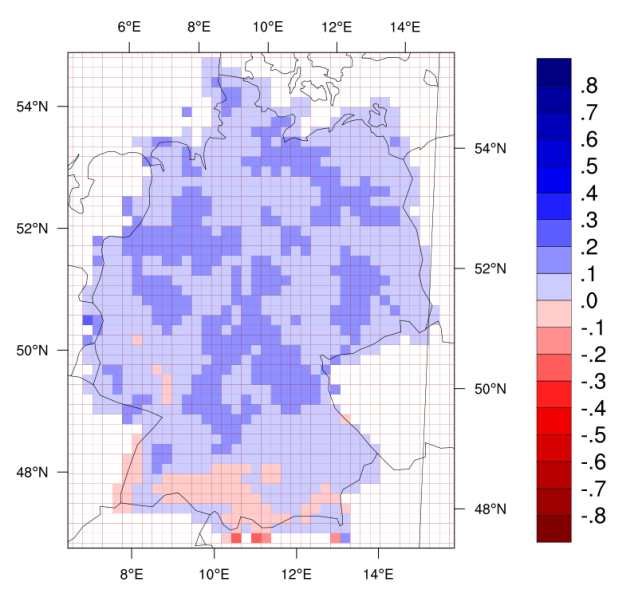

(d) Summer, difference between

CCS uncorrected and corrected

Fig. 6: For 2071-2100, (a) range of climate change signals in SPI between uncorrected scenarios in winter, (b) difference between the mean climate change signal in SPI of bias-corrected and uncorrected model data in winter, (c) range of climate change signals in SPI between uncorrected scenarios in summer, and (d) difference between the mean climate change signal in SPI of bias-corrected and uncorrected model data in summer.

the fluctuations on different timescales, as was suggested by Haerter et al. (2011) for temperature and could be extended for precipitation. Another approach of bias correction using weather type classes may be an alternative accounting for realistic representation of extreme events (Bissoli and Dittmann, 2001).

As regional climate model simulations have deficits in reproducing present-day and projecting future climate, climate model outputs may need to be bias-corrected (Ho et al., 2012). Hagemann et al. (2011) conclude that the influence of the bias correction on the CCS may for some regions be larger than the signal itself. Ehret et al. (2012) point out that the bias correction is likely influencing the climate change signals. We demonstrate in our study that the bias correction method intensifies the CCS towards wetter conditions and show this for the whole of Germany. However, we denote that the spread between the single ensemble members in the climate change signal is larger or twice as large as the difference between the mean CCS of the ensemble members of bias-corrected and uncorrected data. This implies that the sensitivity of the SPI to the modelled precipitation bias is small compared to the range of the climate change signals 


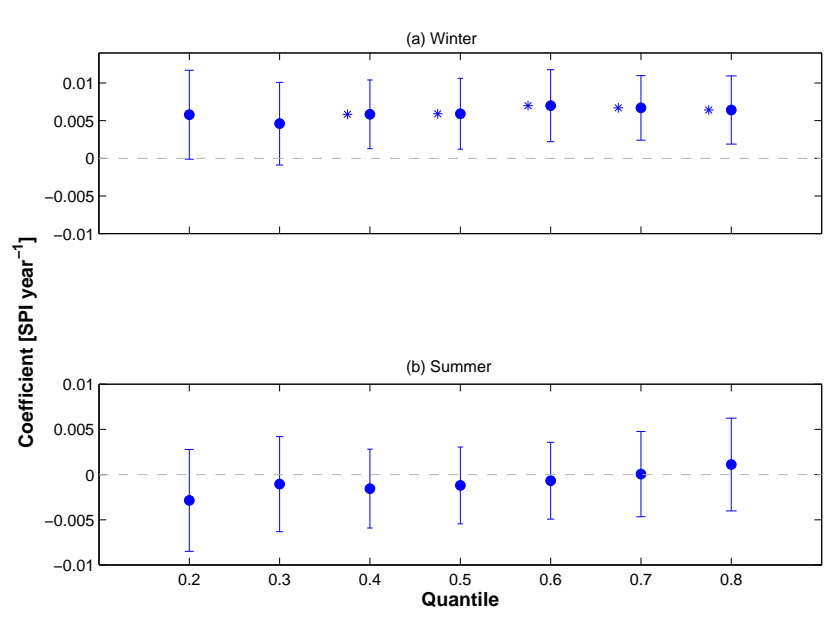

Fig. 7: Quantile regression analysis: ensemble trend coefficients of 0.2-0.8 quantiles for winter (a) and summer (b) SPI time series over the period 1971 to 2100 for Germany. Ensemble standard deviations of the estimated trend coefficients are derived by bootstrapping. Star marks indicate significant trends.

within our ensemble. Therefore, the SPI is a very useful tool for the climate change studies, allowing us to avoid the additional uncertainties caused by bias corrections.

Further analyses with uncorrected data indicate that the climate change signal is similar to the larger-scale projections of IPCC (2007). The results conform to the physical background depicted in the IPCC report of getting more moisture in the studied area through the westerly wind system. The SPI shows a trend towards wetter conditions with high regional variability for both depicted time periods in winter. While SPI projections indicate an overall wetting in summer during 2036-2065, drier summers are projected towards the south-west of Germany for the end of the $21 \mathrm{st}$ century. However, the overall temporal trend across the SPI distribution in summer of the quantile regression analysis is statistically insignificant. This circumstance needs to be explored when associated with above-average temperatures in the future (Hirschi et al., 2011). There is a statistically significant strong wetting pattern (increase) in the upper quantiles of the SPI for winter, meaning that strong precipitation will intensify and the number of dry months will be reduced in winter. Former reviews of climate change in Germany have suggested an increase in winter and decrease in summer precipitation with an increased frequency of both extreme precipitations and droughts (Gerstengarbe et al., 2003). Our results only partly support these findings. According to the CCS we find wetting patterns in the near (2036-2065) future for winter and summer. In addition, we suggest that the changes may not be uniform across the SPI distribution, and show mainly a significant strong increase of wetting in winter with an increase in severity of the heaviest 6-month precipita-
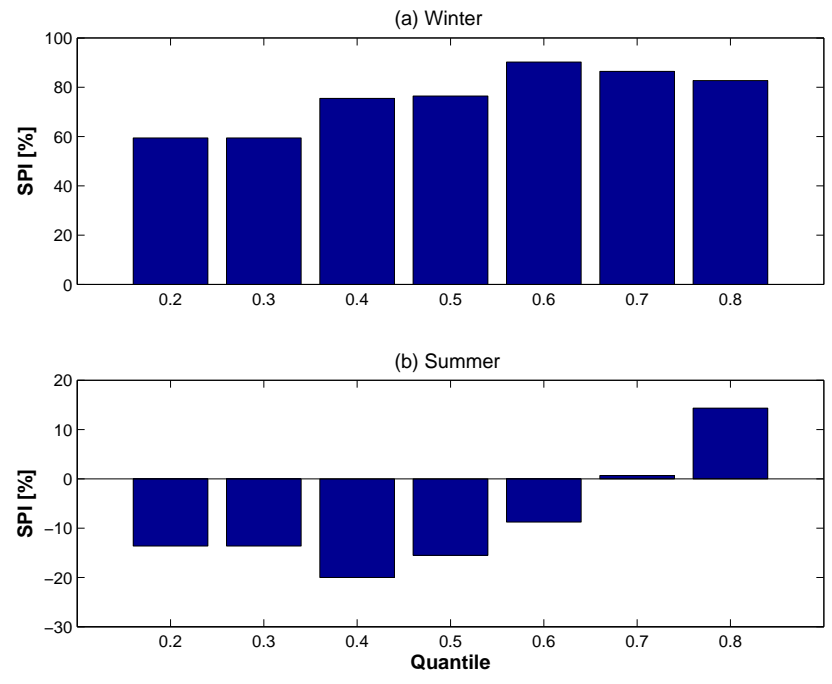

Fig. 8: Percent change in 0.2-0.8 quantiles for winter (a) and summer (b) SPI over the period 1971 to 2100 for Germany.

tion levels (upper quantiles), possibly related to floods. This circumstance might enhance soil erosion risks. Therefore, agroforestry systems or short rotation poplar coppices could level-off erosion (Busch, 2012). For summer, the changes show more variations with a minor increase of about $14 \%$ towards intense wetting as indicated by the upper quantile and a weak increase of moderate drought risks as indicated in quantiles $0.2-0.6$. This implies that weak precipitation will decrease further in the future in summer with a minor shift towards intense precipitation events for summer.

The future increased winter storage of water in the soil via precipitation surplus may introduce long-term memory effects with timescales of several months (Vautard et al., 2007), which may lead to more water availability in spring. This winter soil water surplus could enhance local convective cloud formation and local latent heat fluxes (Schär et al., 1999) thereby decreasing sensible heat fluxes in winter and early spring. As a result soil drying may be delayed to late spring extending into the summer period, which could have an important effect on sensible heat fluxes (Seneviratne et al., 2002).

How future climatic variations might affect the feedback processes in the vegetation-atmosphere system with regard to agroforestry systems or short-rotation poplar coppices should be a subject for further studies including also detrending techniques. However, the impact of change is regionally very different. Therefore, local impact studies using one or multiple crop-specific impact models are required, taking local practices into account to study the relevant effects on agriculture and agroforestry systems and to develop a robust adaption plan. 
Supplementary material related to this article is available online at: http://www.biogeosciences.net/10/ 2959/2013/bg-10-2959-2013-supplement..pdf.

Acknowledgements. We thank the BMBF and the project leader PTJ for their support of the research activities in the framework of the BMBF project BEST (BioEnergy STrengthening). The project is funded by BMBF with contract number 033L033A. We also thank the German Weather Service (DWD) for providing the observational data, and the project KLIFF, funded by the Ministry of Science and Education of Lower Saxony, for providing climate model data. We thank an anonymous person for proofreading the manuscript. Thanks is due to three anonymous reviewers and the editor for their comments.

This Open Access Publication is funded by the University of Göttingen.

Edited by: S. Seneviratne

\section{References}

Anav, A. and Mariotti, A.: Sensitivity of natural vegetation to climate change in the Euro-Mediterranean area, Clim. Res., 46, 277-292, 2011.

Bartholy, J., Pongracz, R., Gelybo, G., and Kern, A.: What Climate Can We Expect in Central/Eastern Europe by 2071-2100?, Bioclimatology and Natural Hazards, 3-14, doi:10.1007/978-14020-8876-6_1, 2009.

Berg, P., Feldmann, H., and Panitz, H.-J.: Bias correction of high resolution regional climate model data, J. Hydrol., 448-449, 8092, 2012.

Bissoli, P. and Dittmann, E.: The objective weather type classification of the German Weather Service and its possibilities of application to environmental and meteorological investigations, Meteorologische Zeitschrift, 10, 253-260, 2001.

Burke, E. J. and Brown, S. J.: Evaluating Uncertainties in the Projection of Future Drought, J. Hydrometeorol., 9, 292-299, 2008.

Busch, G.: GIS-based Tools for Regional Assessments and Planning Processes Regarding Potential Environmental Effects of Poplar SRC, BioEnergy Res., 5, 584-605, 2012.

Christensen, J. H. and Christensen, O. B.: A summary of the PRUDENCE model projections: changes in European climate by the end of this century, Clim. Change, 81, 7-30, doi:1007/s10584006-9210-7, 2007.

Christensen, J. H., Hewitson, B., Busuioc, A., Chen, A., Gao, X., Held, I., Jones, R., Kolli, R. K., Kwon, W.-T., Laprise, R., Rueda, V. M., Mearns, L., Menendez, C. G., Räisänen, J., Rinke, A., Sarr, A., and Whetton, P.: Climate Change 2007: The Physical Science Basis. Contribution of Working Group I to the Fourth Assessment Report of the Intergovernmental Panel on Climate Change, chap. Regional climate projections, Cambridge University Press, Cambridge, United Kingdom, 2007.

DeGaetano, A. T.: A temporal comparison of drought impacts and responses in the New York city metropolitan area, Clim. Change, 42, 539-560, 1999.
Dosio, A. and Paruolo, P.: Bias correction of the ENSEMBLES high-resolution climate change projections for use by impact models: Evaluation of the present climate, J. Geophys. Res., 116, 22 pp, doi:10.1029/2011JD015934, 2011.

DWD: DWD Informationsblatt REGNIE, www.dwd.de/ hydrometeorologie, 2009.

Ehret, U., Zehe, E., Wulfmeyer, V., Warrach-Sagi, K., and Liebert, J.: HESS Opinions "Should we apply bias correction to global and regional climate model data?", Hydrol. Earth Syst. Sci., 16, 3391-3404, 2012.

Galos, B., Lorenz, P., and Jacob, D.: Will dry events occur more often in Hungary in the future?, Environ. Res. Lett., 2, 9 pp, 2007.

Gerstengarbe, F.-W., Badeck, F., Hattermann, F., Krysanova, V., Lahmer, W., Lasch, P., Stock, M., Suckow, F., Wechsung, F., and Werner, P. C.: Studie zur klimatischen Entwicklung im Land Brandenburg bis 2055 und deren Auswirkungen auf den Wasserhaushalt, die Forst- und Landwirtschaft sowie die Ableitung erster Perspektiven, Tech. Rep. Report 83, PIK, Postdam, 2003.

Haerter, J. O., Hagemann, S., Moseley, C., and Piani, C.: Climate model bias correction and the role of timescales, Hydrol. Earth Syst. Sci., 15, 1065-1079, doi:10.5194/hess-15-10652011, 2011.

Hagemann, S., Göttel, H., Jacob, D., Lorenz, P., and Roeckner, E.: Improved regional scale processes reflected in projected hydrological changes over large European catchments, Clim. Dynam., 32, 767-781, 2009.

Hagemann, S., Chen, C., Haerter, J. O., Heinke, J., Gerten, D., and Piani, C.: Impact of a statistical bias correction on the projected hydrological changes obtained from three GCMs and two hydrological models, J. Hydrometeorol., 12, 556-578, 2011.

Heinrich, G. and Gobiet, A.: The future of dry and wet spells in Europe: A comprehensive study based on the ENSEMBLES regional climate models, Int. J. Climatol., 32, 1951-1970, doi:10.1002/joc.2421, 2012.

Hewitt, C. D.: Ensembles-based predictions of climate changes and their impacts, Eos Trans. AGU, 85, 566, doi:10.1029/2004EO520005, 2004.

Hirschi, M., Seneviratne, S. I., Alexandrov, V., Boberg, F., Boroneant, C., Christensen, O. B., Formayer, H., Orlowsky, B., and Stepanek, P.: Observational evidence for soil-moisture impact on hot extremes in southeastern Europe, Nat. Geosci., 4 , 17-21, doi:10.1038/NGEO1032, 2011.

Ho, C. K., Stephenson, D. B., Collins, M., Ferro, C. A. T., and Brown, S. J.: Calibration Strategies: A source of additional uncertainty in climage change projections, Bull. Am. Meteorol. Soc., 93, 21-26, 2012.

Iglesias, A., Garrote, L., and S. Quiroga, M. M.: From climate change impacts to the development of adaption strategies: challenges for agriculture in Europe, Clim. Change, 143-168, doi:10.1007/10584-011-0344-x, 2012.

IPCC: Emission Scenarios, Cambridge University Press, Cambridge, United Kingdom, 2007.

Jacob, D., Bärring, L., Christensen, O. B., Christensen, J. H., de Castro, M., Deque, M., Giorgi, F., Hagemann, S., Hirschi, M., Jones, R., Kjellström, E., Lenderink, G., Rockel, B., Sanchez, E., Schär, C., Seneviratne, S. I., Somot, S., van Ulden, A., and van den Hurk, B.: An inter-comparison of regional climate models for Europe: model performance and present-day climate, Clim. Change, 81, 31-52, doi:10.1007/s10584-006-9213- 
4, 2007

Jacob, D., Bülow, K., Kotova, L., Moseley, C., Petersen, J., and Recchid, D.: Regionale Klimaprojektionen für Europa und Deutschland: Ensemble-Simulationen für die Klimafolgenforschung, CSC Report 6, Climate Service Center, 2012.

Kalbarczyk, R.: Temporal and spatial diversity of the occurrence of atmospheric drought in Poland (1966-2005) and its effect of yield of pickling cucumber (Cucumis sativus L.), Spanish Journal of Agricultural Research, 8, 1147-1162, 2010.

Koenker, R. and Hallock, K.: Quantile regression, Journal of Economical Perspectives, 15, 143-156, 2001.

Kundzewicz, Z. W.: Water resources systems - hydrological risk management and development, chap. Extreme precipitation and floods in the changing world, 32-39, 281, IAHS Publ., 2003.

Lana, X., Serra, C., and Burgueno, A.: Patterns of monthly rainfall shortage and excess in terms of the standardized precipitation index for Catalonia (NE Spain), Int. J. Climatol., 21, 1669-1691, 2001.

Lloyd-Hughes, B. and Saunders, M. A.: A drought climatology for Europe, Int. J. Climatol., 22, 1571-1592, 2002.

McKee, T. B., Doesken, N. J., and Kleist, J.: The Relationship of Drought Frequency and Duration to Timescales, in: Eigth Conference on Applied Climatology, 1993.

Meehl, G. A., Stocker, T. F., Collins, W. D., Friedlingstein, P., Gaye, A. T., Gregory, J. M., Kitoh, A., Knutti, R., Murphy, J. M., Noda, A., Raper, S. C. B., Watterson, I. G., Weaver, A. J., and Zhao, Z.-C.: Global Climate Projections, in: Climage Change 2007: The Physical Science Basis, Contribution of Working Group I to the Fouth Assessment Report of the Intergovernmental Panel on Climate Change, edited by: Solomon, S., Qin, D., Manning, M., Chen, Z., Marquis, M., Averyt, K. B., Tignor, M., and Miller, H. L., Cambridge University Press, Cambridge, United Kingdom and New York, NY, USA, 2007.

MPI-M: Klimaprojektionen für das 21. Jahrhundert, Max-PlanckInstitut für Meteorologie, Bundesstrasse 53, D-20146 Hamburg, 2006.

Mudelsee, M., Chirila, D., Deutschländer, T., Döring, C., Haerter, J., Hagemann, S., Hoffmann, H., Jacob, D., Krahe, P., Lohmann, G., Moseley, C., Nilson, E., Panferov, O., Rath, T., and Tinz, B.: Climate Model Bias Correction und die Deutsche Anpassungsstrategie, Meteorologische Zeitschrift, 03, 2-7, 2010.

Nakicneovic, N., Alcamo, J., Davis, C., de Vries, B., Fenhann, J., Gaffin, S., Gregory, K., Grubler, A., Jund, T. Y., Kram, T., Rovere, E. L. L., Michaelis, L., Mori, S., Morita, T., Papper, W., Pitcher, H., Price, L., Riahi, K., Roehrl, A., Rogner, H.-H., Sankovski, A., Schlesinger, M., Shukla, P., Smith, S., Swart, R., van Rooijen, S., Victor, N., and Dadi, Z.: Emission scenarios. A special report of Working Group III of the Intergovernmental Panel on Climate Change, Cambridge University Press, Cambridge, United Kingdom, 2000.

Olesen, J. E., Carter, T. R., Diaz-Ambrona, C. H., Fronzek, S., Heidmann, T., Hickler, T., Holt, T., Minguez, M. I., Morales, P., Palutikof, J. P., Quemada, M., Ruiz-Ramos, M., Rubak, G. H., Sau, F., Smith, B., and Sykes, M. T.: Uncertainties in projected impacts of climate change on European agriculture and terrestrial ecosystems based on scenarios from regional climate models, Clim. Change, 81, 123-143, doi:10.1007/s10584-006-9216$1,2007$.
Palmer, W. C.: Meteorological drought, United States Weather Bureau, Research Paper No. 45, 1965.

Palutikof, J. P., Agnew, M. D., and Hoar, M. R.: Public perceptions of unusually warm weather in the UK: impacts, responses and adaptions, Clim. Res., 26, 43-59, 2004.

Patel, N. R., Chopra, P., and Dadhwal, V. K.: Analyzing spatial patterns of meteorological drought using standardized precipitation index, Meteorol. Appl., 14, 329-336, 2007.

Pausas, J. G.: Changes in fire and climate in the eastern Iberian Peninsula (Mediterranean Basin), Clim. Change, 63, 337-350, 2004.

Piani, C., Weedon, G. P., Best, M., Gomes, S. M., Viterbo, P., Hagemann, S., and Haerter, J. O.: Statistical bias correction of global simulated daily precipitation and temperature for the application of hydrological models, J. Hydrol., 395, 199-215, 2010.

Roeckner, E., Brokopf, R., Esch, M., Giorgetta, M., Hagemann, S., and Kornblueh, L.: Sensitivity of simulated climate to horizontal and vertical resolution in the ECHAM5 atmosphere model, J. Climate, 19, 3771-3791, 2006.

Schär, C., Lüthi, D., and Beyerle, U.: The Soil-Precipitation Feedback: A Process Study with a Regional Climate Model, J. Climate, 12, 722-741, 1999.

Schär, C., Vidale, P. L., Luthi, D., Frei, C., Häberli, C., Liniger, M. A., and Appenzeller, C.: The role of increasing temperature variability in European summer heatwaves, Nature, 427, 332336, 2004.

Sen, B., Topcu, S., Türkes, M., Sen, B., and Warner, J. F.: Projecting climate change, drought conditions and crop productivity in Turkey, Clim. Res., 52, 175-191, 2012.

Seneviratne, S. I., Pal, J. S., Eltahir, E. A. B., and Schär, C.: Summer dryness in a warmer climate: a process study with a regional climate model, Clim. Dynam., 20, 69-85, doi:10.1007/s00382002-0258-4, 2002.

Seneviratne, S. I., Nicholls, N., Easterling, D., Goodess, C. M., Kanae, S., Kossin, J., Luo, Y., Marengo, J., McInnes, K., Rahimi, M., Reichstein, M., Sorteberg, A., Vera, C., and Zhang, X.: Managing the Risks of Extreme Events and Disasters to Advance Climate Change Adaptation. in: Changes in climate extremes and their impacts on the natural physical environment, in: A Special Report of Working Groups I and II of the Intergovernmental Panel on Cliamte Change (IPCC), edited by Field, C. B., Barros, V., Stocker, T. F., Qin, D., Dokken, D. J., Ebi, K. L., Mastrandrea, M. D., MAch, K. J., Plattner, G. K., Allen, S. K., Tignor, M., and Midgley, P. M., pp. 109-230, Cambridge University Press, Cambridge, United Kingdom, and New York, NY, USA, 2012.

Subash, N. and Mohan, H. S. R.: Trend detection in rainfall and evaluation of standardized precipitation index as a drought assessment index for rice - wheat productivity over IGR in India, Int. J. Climatol., 31, 1694-1709, 2011.

Teutschbein, C. and Seibert, J.: Bias correction of regional climate model simulations for hydrological climate-change impact studies: Review and evaluation of different methods, J. Hydrol., 456457, 12-29, doi:10.1016/j.jhydrol.2012.05.052, 2012.

Themessl, M. J., Gobiet, A., and Leuprecht, A.: Empiricalstatistical downscaling and error correction of daily precipitation from regional climate models, Int. J. Climatol., 31, 1530-1544, 2011.

van der Linden, P. and Mitchell, J. F. B.: ENSEMBLES: Climate Change and its Impacts: Summary of research and results from 
the ENSEMBLES project, Tech. rep., Met Office Hadley Centre, Fitz Roy Road, Exeter EX1 3PB, UK, 160, 2009.

Vautard, R., Yiou, P., D’Andrea, F., de Noblet, N., Viovy, N., Cassou, C., Polcher, J., Ciais, P., Kageyama, M., and Fan, Y.: Summertime European heat and drought waves induced by wintertime Mediterranean rainfall deficit, Geophys. Res. Lett., 34, L07711, doi:10.1029/2006GL28001, 2007.

Wilhite, D. A., Hayes, M. J., Knutson, C., and Smith, K. H.: Planning for drought: moving from crisis to risk management, J. Am. Water Resour. As., 36, 697-710, 2000.
Will, A., Keuler, K., and Block, A.: The Climate Local Model - evaluation results and recent developments, TerraFLOPS Newsletter, 8, 2-3, 2006.

Wu, H., Hayes, M. J., Wilhite, D. A., and Svoboda, M. D.: The effect of the length of record on the standardized precipitation index calculation, Int. J. Climatol., 25, 505-520, 2005.

Zaitchik, B. F., Macaldy, A. K., Bonneau, L. R., and Smith, R. B.: Europe's 2003 heat wave: A satellite view of impacts and land atmosphere feedbacks, Int. J. Climatol., 26, 743-769, 2006. 